\title{
Fine Control of the Release and Encapsulation of Fe lons in Dendrimers through Ferritin-like Redox Switching
}

\author{
Reina Nakajima, Masanori Tsuruta, Masayoshi Higuchi, and Kimihisa Yamamoto* \\ Department of Chemistry, Faculty of Science and Technology, Keio University, Yokohama 223-8522, Japan
}

Experimental section

(1) General

The NMR spectra were recorded using a JEOL JMN400 FT-NMR spectrometer $(400 \mathrm{MHz})$ in $\mathrm{CDCl}_{3}+\mathrm{TMS}_{(\mathrm{internal}}$ standard) solution. The MALDI TOF-Mass spectra were obtained using a Shimadzu/Kratos KOMPACT MALDI mass spectrometer (Positive mode, Matrix: Dithranol). The UV-vis spectra were recorded using a Shimadzu UV-3100PC spectrometer with a sealed quartz cell (optical path length: For the titration; $1 \mathrm{~cm}$. For electro UV-vis spectroscopy; $1 \mathrm{~mm}$.). Cyclic voltammograms were recorded using an ALS 440 electrochemical analyzer. A glassy carbon electrode was used as the working electrode, which was polished with $0.05 \mathrm{~mm}$ alumina paste before the analysis. The counter and the reference electrodes are Pt wire and $\mathrm{Ag} / \mathrm{Ag}^{+}$, respectively. Potentials are compensated by the redox potential of the $\mathrm{Fc} / \mathrm{Fc}^{+}$couple in acetonitrile.

(2) Chemicals

4,4'-Diaminobenzophenone was purchased from Fluka. Iron (III) chloride was from MERCK. Iron (II) chloride was from the Aldrich Chemical Company, Inc. All other chemicals were purchased from the Kantoh Kagaku Co.

(3) Synthesis

All DPAs were synthesized by a previously reported method ${ }^{1}$.

Chart S1. Structure of $\left(\mathrm{FeCl}_{3}\right)_{30} @$ Phenylazomethine Dendrimer Genreration 4. DPA G4 has 30 imine sites that act as strong coordination sites with $\mathrm{Fe}^{3+}$ ions.

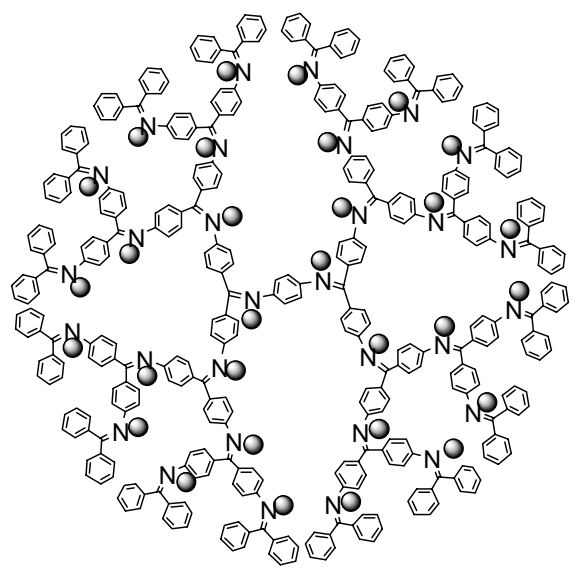

O $: \mathrm{FeCl}_{3}$

${ }^{1}$ Higuchi, M.; Shiki, S.; Ariga, K.; Yamamoto, K. J. Am. Chem. Soc. 2001, 123, 4414. 
About Isosbestic point

We used UV-vis spectroscopy to monitor the complexation behavior and defined the radial stepwise complexation fashion by the isosbestic points. When each imine (I) in the DPA forms a 1:1 complex (IM) with a metal (M), there is one equilibrium through the complexation.

$$
\mathrm{I}+\mathrm{M} \leftrightarrow \mathrm{IM} \text { eq. } 1
$$

The total concentration of imines, $\left([I]_{t}\right)$ corresponds to the total concentration of DPA during the addition of metal ions. The absorption is expressed by the sum of the absorptions of all compounds in the solution,

$$
\text { Abs. }=\varepsilon_{\mathrm{I}}[\mathrm{I}]+\varepsilon_{\mathrm{M}}[\mathrm{M}]+\varepsilon_{\mathrm{IM}}[\mathrm{IM}] \quad \text { eq. } 2
$$

Where [I] is the concentration of the free imine, $[\mathrm{M}]$ is that of the free metal, $[\mathrm{IM}]$ is that of the complex, and $\varepsilon$ is the absorption coefficient of each compound. Eq. 2 can be ordered by using the total concentration of the imine $[\mathrm{I}]_{\mathrm{t}}$ and the metal $[\mathrm{M}]_{\mathrm{t}}$ expressed as $[\mathrm{I}]_{\mathrm{t}}=[\mathrm{I}]+[\mathrm{IM}]=$ constant and $[\mathrm{M}]_{\mathrm{t}}=[\mathrm{M}]+[\mathrm{IM}]$.

$$
\text { Abs. }=\varepsilon_{\mathrm{I}}[\mathrm{I}]_{\mathrm{t}}+\varepsilon_{\mathrm{M}}[\mathrm{M}]_{\mathrm{t}}+[\mathrm{IM}]\left(\varepsilon_{\mathrm{IM}}-\varepsilon_{\mathrm{I}}-\varepsilon_{\mathrm{M}}\right) \quad \text { eq. } 3
$$

If metal does not possess an absorption in the range of monitoring (i.e., $\varepsilon_{\mathrm{M}}=0$ ),

$$
\text { Abs. }=\varepsilon_{\mathrm{I}}[\mathrm{I}]_{\mathrm{t}}+[\mathrm{IM}]\left(\varepsilon_{\mathrm{IM}}-\varepsilon_{\mathrm{I}}\right) \quad \text { eq. } 4
$$

The isosbestic point was observed when the absorption is consistent at $\lambda$, where $\left(\varepsilon_{\mathrm{IM}}-\varepsilon_{\mathrm{I}}\right)$ is zero ${ }^{2}$.

In the case of $\mathrm{FeCl}_{3}$, there are absorptions at $\lambda_{\max }=310$ and $360 \mathrm{~nm}$ (i.e., $\varepsilon_{\mathrm{M}} \neq 0$ ).

$$
\text { Abs. }-\varepsilon_{\mathrm{M}}[\mathrm{M}]_{\mathrm{t}}=\varepsilon_{\mathrm{I}}[\mathrm{I}]_{\mathrm{t}}+[\mathrm{IM}]\left(\varepsilon_{\mathrm{IM}}-\varepsilon_{\mathrm{I}}-\varepsilon_{\mathrm{M}}\right) \quad \text { eq. } 5
$$

When subtracting the absorption of the metal, $\left(\varepsilon_{\mathrm{M}}[\mathrm{M}]_{\mathrm{t}}\right)$, from each spectra, the isosbestic point is observed. In this way, the observed isobestic point shows that one equilibrium (eq.1) exists during the titration. The shift in isosbestic points means that there are some imines whose environment is different. By comparing the equivalent of the added $\mathrm{FeCl}_{3}$ with the number of imine sites in each layer, we confirmed the stepwise radial complexation property of DPA.

2 Yamamoto, K.; Higuchi, M.; Shiki, S.; Tsuruta, M.; Chiba, H. Nature 2002, 415, 509. Imaoka, T.; Horiguchi, H.; Yamamoto, K. J. Am. Chem. Soc. 2003, 125, 340. 

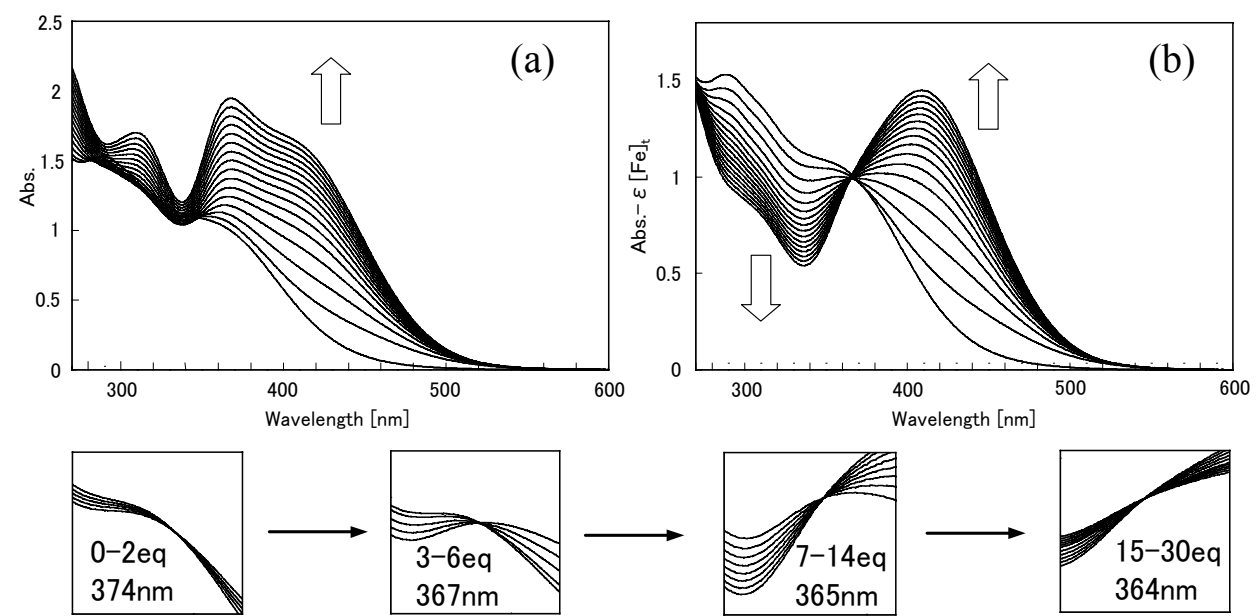

Figure S1. UV-vis spectra changes during the addition of $\mathrm{FeCl}_{3}$ to DPA G4 in $\mathrm{CH}_{3} \mathrm{CN} / \mathrm{CHCl}_{3}=1 / 1$. DPA G4; $5.62 \times 10^{-6} \mathrm{M}, \mathrm{FeCl}_{3} ; 5.62 \times 10^{-3} \mathrm{M}$. $3 \mu 1 \mathrm{FeCl}_{3}$, which is equimolor with DPA, is repeatedly added to the DPA G4 solution. (a) Raw data. (b) After the subtraction of the absorption of $\mathrm{FeCl}_{3}$. (Under) Enlargements focusing on the isosbestic points. 

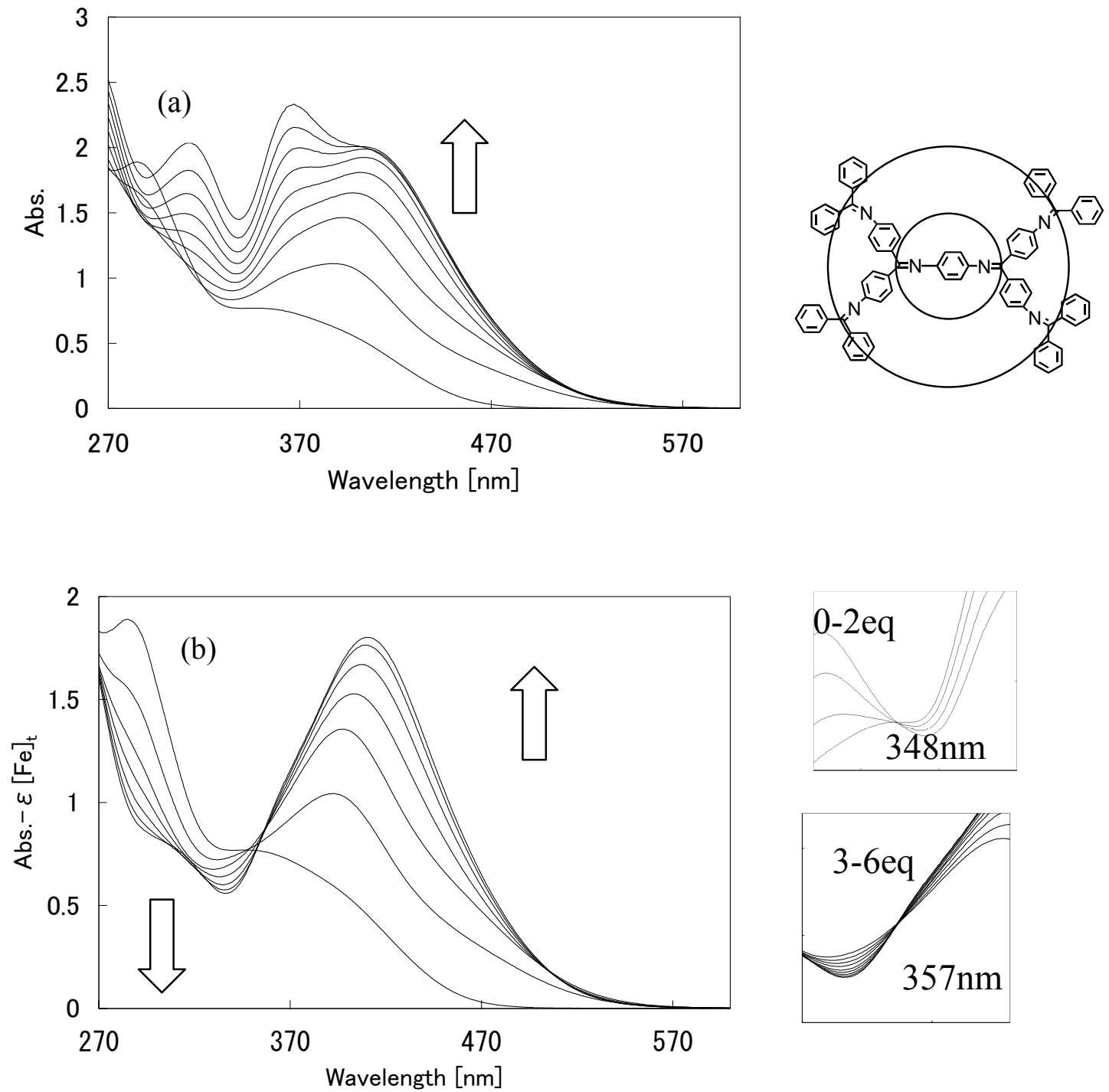

Figure S2. (a) UV-vis spectra changes during the addition of $\mathrm{FeCl}_{3}$ to DPA G2 in $\mathrm{CH}_{3} \mathrm{CN} / \mathrm{CHCl}_{3}=1 / 1$. DPA G2; 2.72 $\times 10^{-5} \mathrm{M}, \mathrm{FeCl}_{3} ; 1.63 \times 10^{-2} \mathrm{M} .5 \mu 1 \mathrm{FeCl}_{3}$, which is equimolor with DPA, is repeatedly added to the DPA G2 solution. (Right) The structure of DPA G2. (b) After subtracting the absorption of $\mathrm{Fe}^{3+}$. (Right) Enlargements focusing on the isosbestic points. Isosbestic point at the 0-2eq addition of $\mathrm{FeCl}_{3}$ differs from that of the 3-6eq addition. 

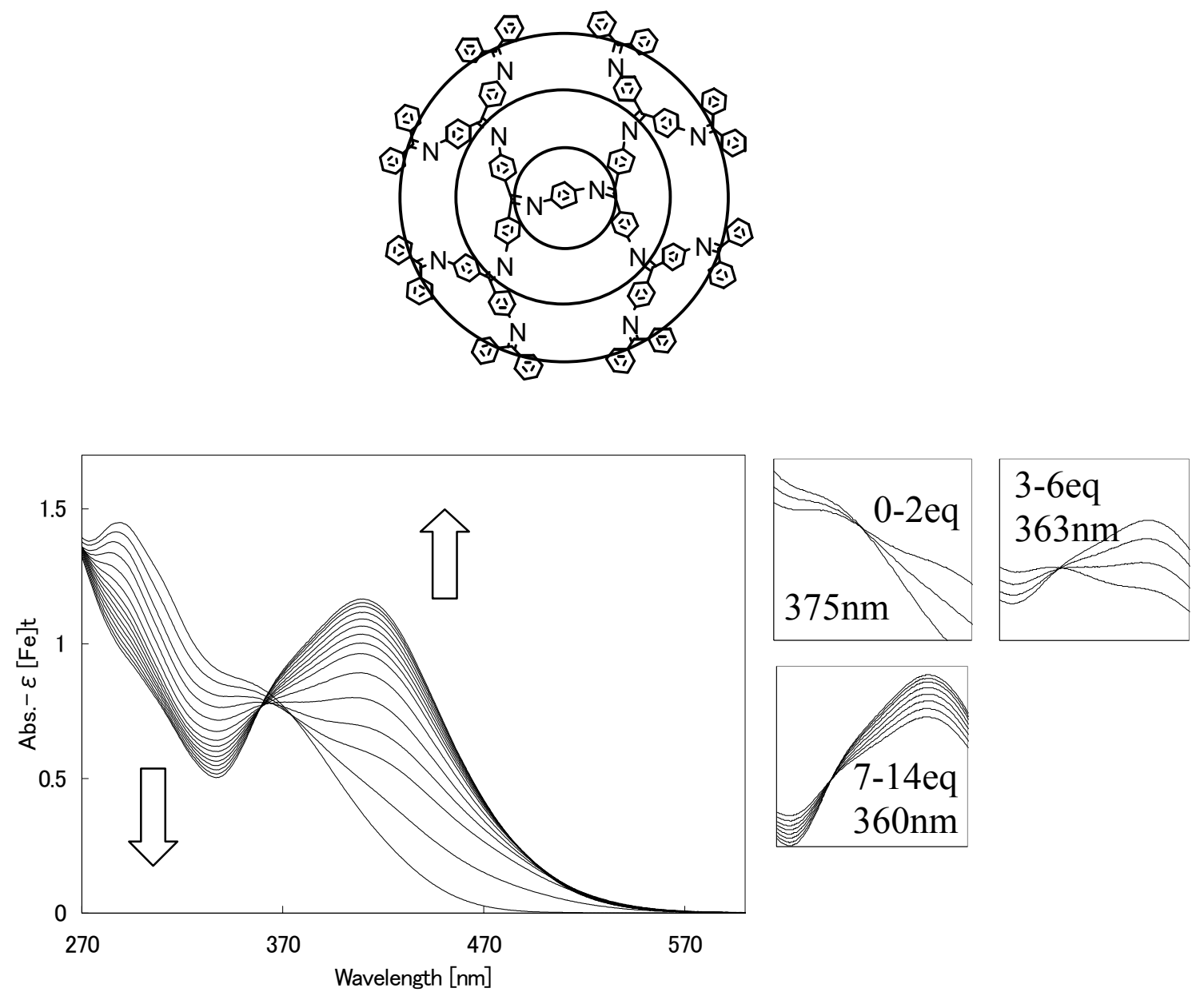

Figure S3. UV-vis spectra changes during the addition of $\mathrm{FeCl}_{3}$ to DPA G3 in $\mathrm{CH}_{3} \mathrm{CN} / \mathrm{CHCl}_{3}=1 / 1$. DPA G3; $9.30 \times$ $10^{-6} \mathrm{M}, \mathrm{FeCl}_{3} ; 5.55 \times 10^{-3} \mathrm{M}$. $5 \mu 1 \mathrm{FeCl}_{3}$, which is equimolor with DPA, is repeatedly added to the DPA G3 solution. (Above) The structure of DPA G3. (Right) Enlargements focusing on isosbestic points. Isosbestic points appeared for $0-2,3-6$, and 7-14eq of $\mathrm{FeCl}_{3}$. 

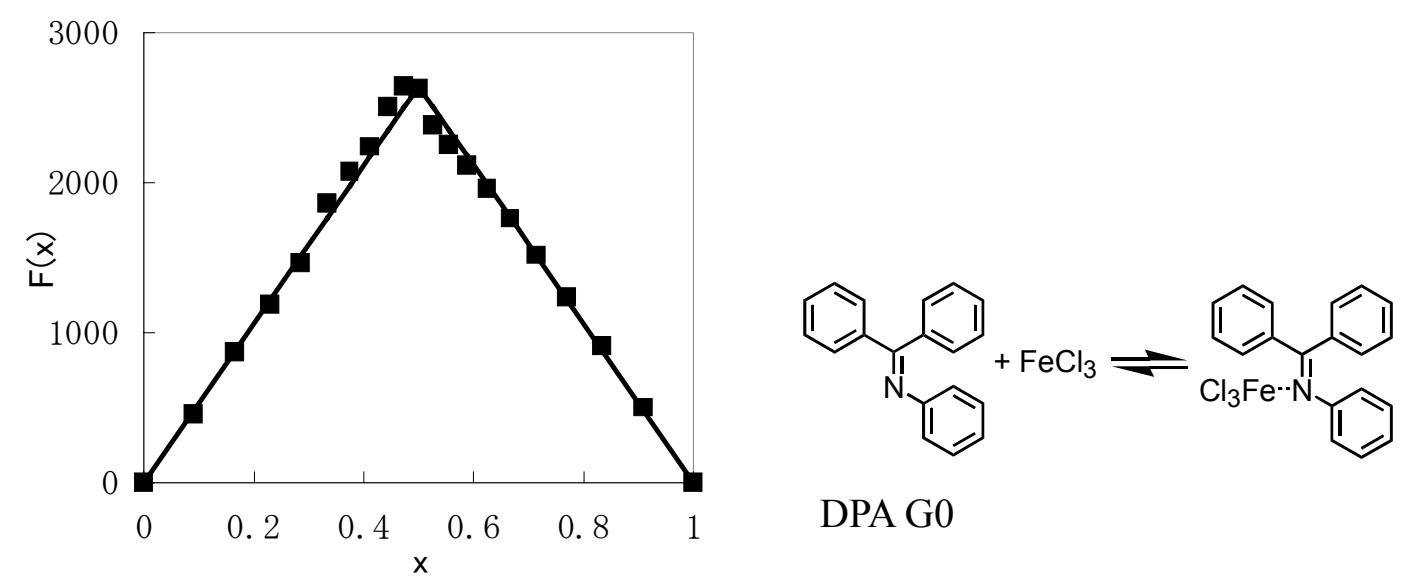

DPA G0

Fgure S4. A Job plot ${ }^{3}$ of $\mathrm{FeCl}_{3}$ and DPA G0. $\mathrm{F}(\mathrm{x})=$ Abs. $/\left(\mathrm{C}_{\mathrm{G} 0}+\mathrm{C}_{\mathrm{FeCl} 3}\right)-\left(\varepsilon_{\mathrm{G} 0}-\varepsilon_{\mathrm{FeCl} 3}\right) \mathrm{x}-\varepsilon_{\mathrm{FeCl} 3}, \quad \mathrm{x}=\mathrm{C}_{\mathrm{G} 0} /\left(\mathrm{C}_{\mathrm{G} 0}+\right.$ $\mathrm{C}_{\mathrm{FeCl} 3}$ ); molar fraction of DPA G0. The solutions of DPA G0 and $\mathrm{FeCl}_{3}$ (with same concentration, $3.45 \times 10^{-4} \mathrm{M}^{-1}$ ) in chloroform/acetonitrile (1/1) were mixed in various proportions. The plot shows a maximum at a 0.5 mole fraction of DPA G0. This means that the imine forms a 1:1 complex with $\mathrm{FeCl}_{3}$ (Right). The equilibrium constant of complexation, $\mathrm{K}$, was determined to be more than $10^{8}\left[\mathrm{M}^{-1}\right]$ by curve fitting a theoretical simulation (eq. 6) to the experimental data.

$$
\begin{aligned}
& \mathrm{F}(\mathrm{x})=(\Delta \varepsilon / \mathrm{C}) \quad B-\sqrt{B^{2}} \\
& \Delta \varepsilon=\varepsilon_{\text {complex }}-\left(\varepsilon_{\mathrm{GO}}+\varepsilon_{\mathrm{FeCl}}\right) \\
& \mathrm{C}=\mathrm{C}_{\mathrm{G}}+\mathrm{C}_{\mathrm{FeCl} 3} \\
& \mathrm{~B}=\mathrm{C}+\mathrm{K}^{-1}
\end{aligned}
$$

eq. 6

3 Job, P. Ann. Chim 1928, 9, 113.

Vosburgh, W. C.; Cooper, R. G. J. Am. Chem. Soc. 1941, 63, 437.

Hill, Z. D.; MacCarthy, P. J. Chem. Educ. 1986, 63, 162. 


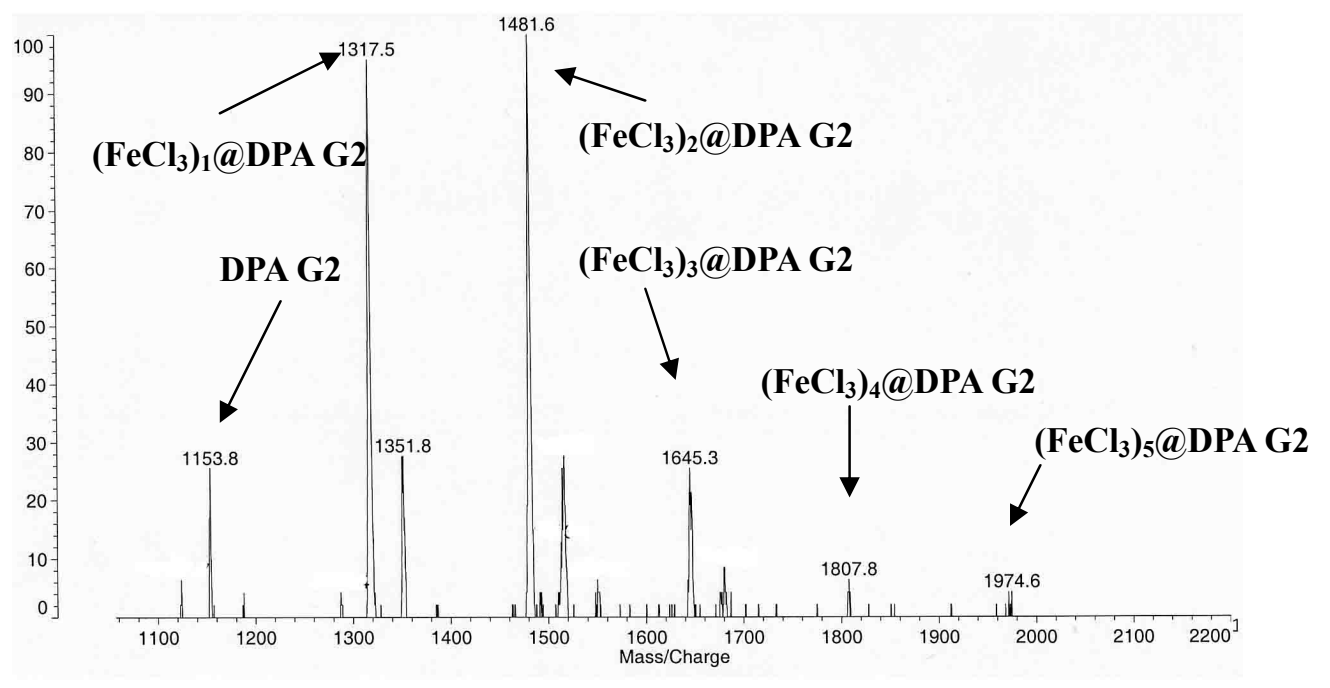

Figure S5. MALDI TOF-MS spectra of $\left(\mathrm{FeCl}_{3}\right)_{6} @$ DPA G2. It is difficult to detect the molecular fragment because of the low ionization activity of the complex during the measurement.

Table S1. MS spectra data of $\left(\mathrm{FeCl}_{3}\right)_{6} @ \mathrm{DPA} \mathrm{G} 2$. (n=number of $\left.\mathrm{FeCl}_{3}, \mathrm{Fw} .162 .21\right)$ The observed molecular fragments of $\left(\mathrm{FeCl}_{3}\right)_{\mathrm{n}} @ \mathrm{DPA} \mathrm{G} 2(\mathrm{n}=0-5)$ confirm that $\mathrm{FeCl}_{3}$ incorporates with DPA through complexation.

\begin{tabular}{llllllll}
$\mathrm{n}$ & 0 & 1 & 2 & 3 & 4 & 5 & 6 \\
\hline calcd & 1153.5 & 1315.2 & 1477.4 & 1639.6 & 1801.8 & 1964.1 & 2126.3 \\
found & 1153.8 & 1317.5 & 1481.6 & 1645.3 & 1807.8 & 1974.6 & -
\end{tabular}




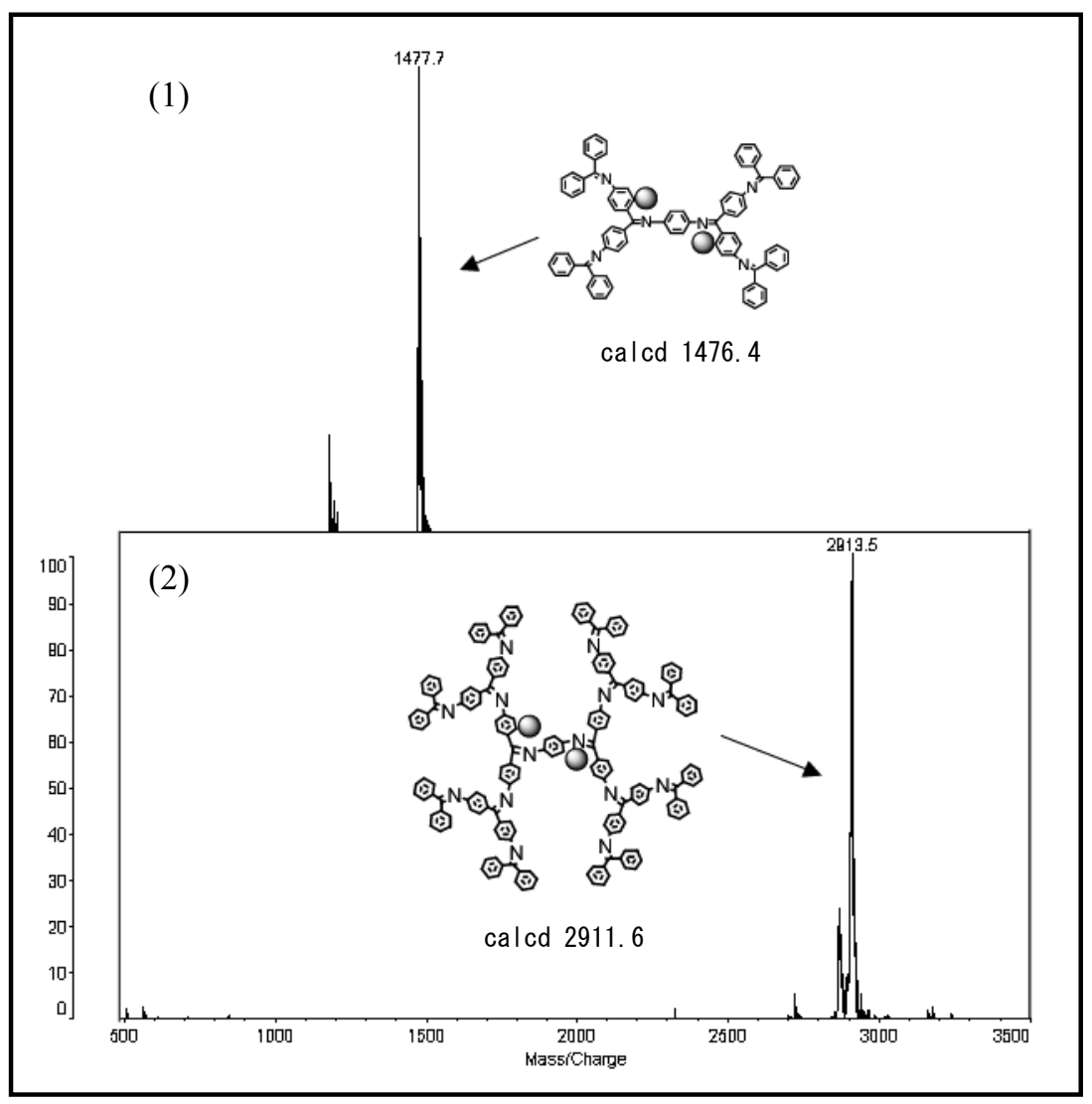

Figure S6. MALDI TOF-MS spectra of (1) $\left(\mathrm{FeCl}_{3}\right)_{2} @ \mathrm{DPA} \mathrm{G} 2$ and (2) $\left(\mathrm{FeCl}_{3}\right)_{2} @ \mathrm{DPA}$ G3. The exact mass of these complexes were found ((1) calcd 1476.4, found 1477.7. (2) calcd 2911.6, found 2913.5). The characterization of Fe@DPA complex was done by Figures S5 and S6. 


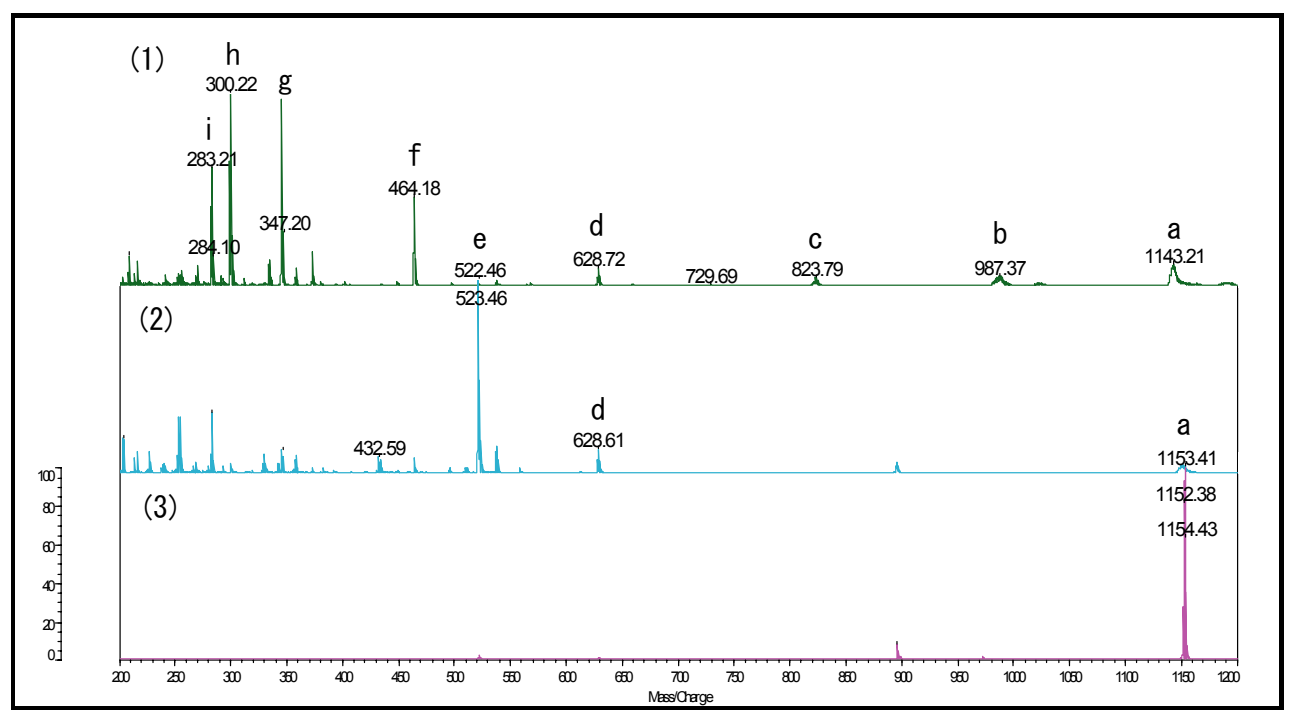

Figrure S7. MALDI TOF-MS spectra of (1) $\left(\mathrm{FeCl}_{3}\right)_{6} @ \mathrm{DPA} \mathrm{G} 2$, (2) $\left(\mathrm{FeCl}_{3}\right)_{2} @ \mathrm{DPA}$ G2, and (3) DPA G2 when the laser's power is high. The specific sites where the imine complex $\mathrm{FeCl}_{3}$ are identified because $\mathrm{C}=\mathrm{N}$ bonds are weaken due to making a complex. (Compare the experimental data with the calculated mass (Figure S8).)

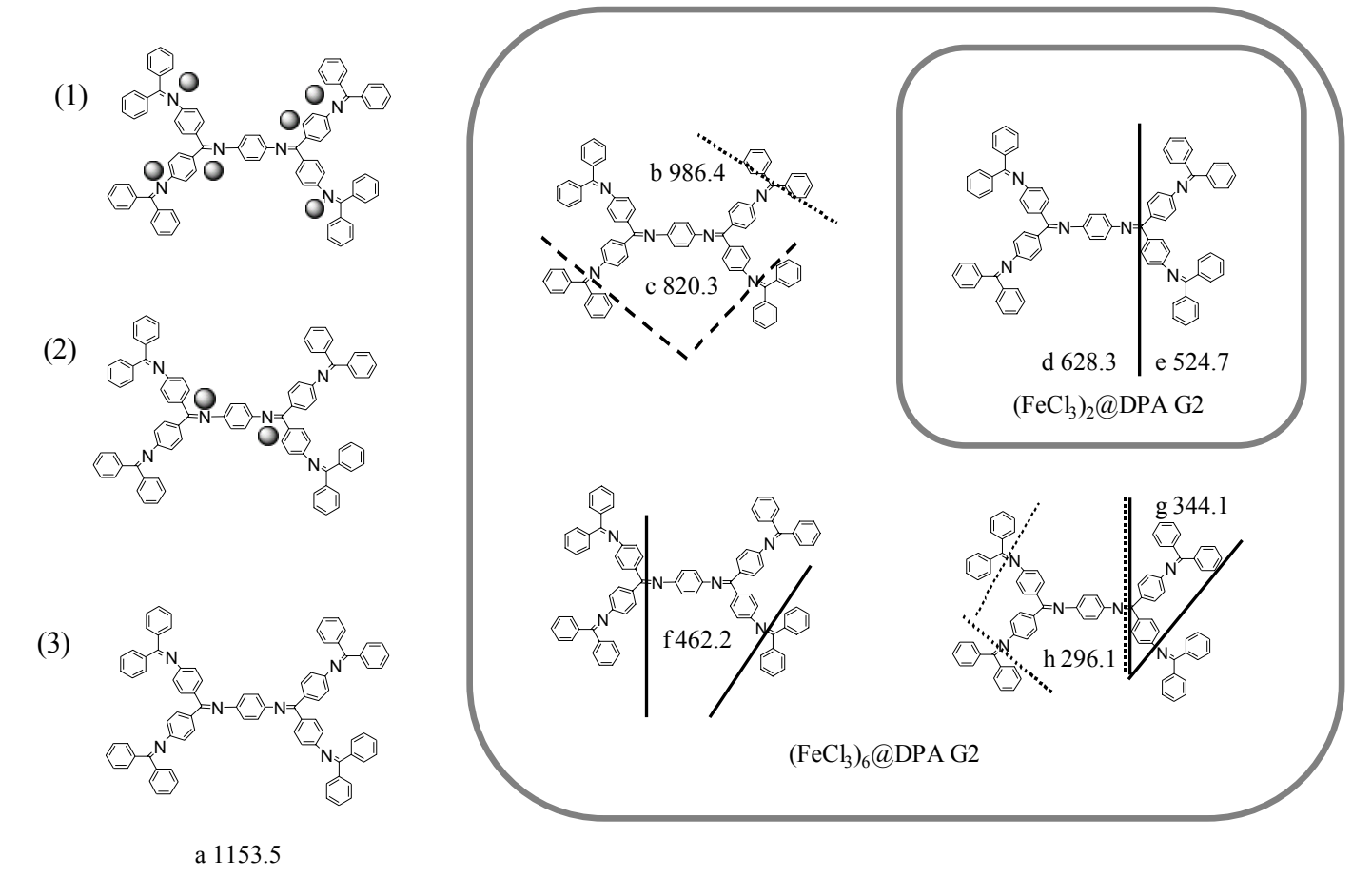

Figure S8. Calculated masses of fragments. Compared with the experimental data (Figure S7), it shows the locations of imines complexing Fe ions. The radial stepwise complexation fashion was confirmed using MS measurement. (1) $\left(\mathrm{FeCl}_{3}\right)_{6} @ \mathrm{DPA} \mathrm{G2}$; calcd 986.4, 820.3, 628.3, 524.7, 462.2, 344.1, 296.1, found 987.4, 823.8, 628.7, 522.5, 464.2, 347.2, 300.22. (2) $\left(\mathrm{FeCl}_{3}\right)_{2} @$ DPA G2; calcd 628.3, 524.7, found 628.6, 523.5. 


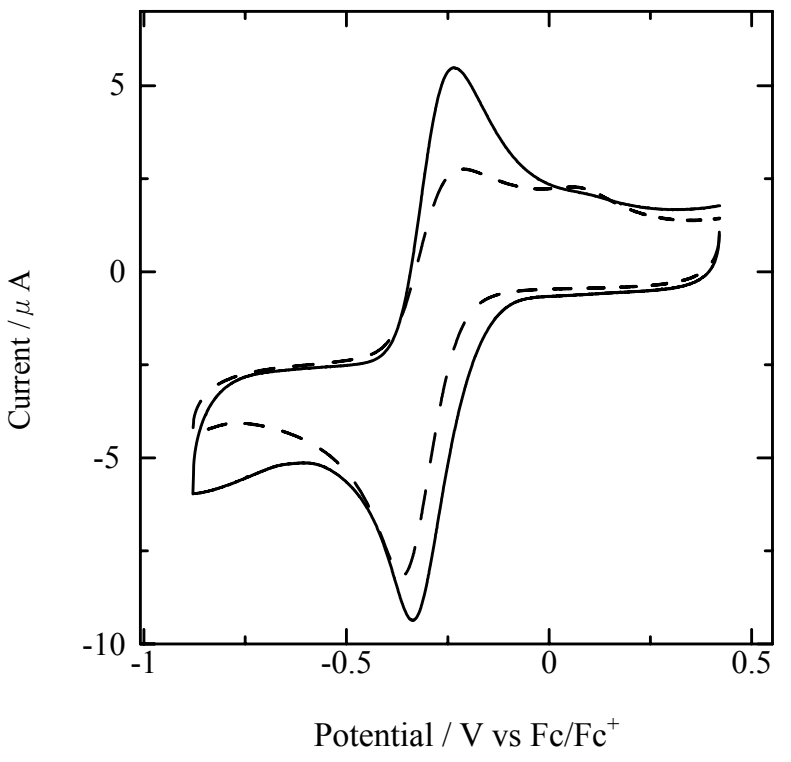

Figure S9. Cyclic voltammograms of $\left(\mathrm{FeCl}_{3}\right)_{\mathrm{n}}$ @DPA G4 under an argon atmosphere. The concentration of $\mathrm{FeCl}_{3}$ in each solution is $0.5 \mathrm{mM}$. Solid line: $\left(\mathrm{FeCl}_{3}\right)_{30} @ \mathrm{DPA} \mathrm{G} 4$, dashed line: $\left(\mathrm{FeCl}_{3}\right)_{2} @ \mathrm{DPA}$ G4. Scan rate: 0.1V/s. Measurements were performed on a glassy carbon disk electrode $(\Phi=3 \mathrm{~mm})$ in $\mathrm{CH}_{3} \mathrm{CN} / \mathrm{CHCl}_{3}=1 / 1+0.1 \mathrm{M} \mathrm{TBABF}$. Although $\left(\mathrm{FeCl}_{3}\right)_{30} @$ DPA G4 shows a reversible redox wave, $\left(\mathrm{FeCl}_{3}\right)_{2} @ \mathrm{DPA}$ G4 shows an irreversible wave.
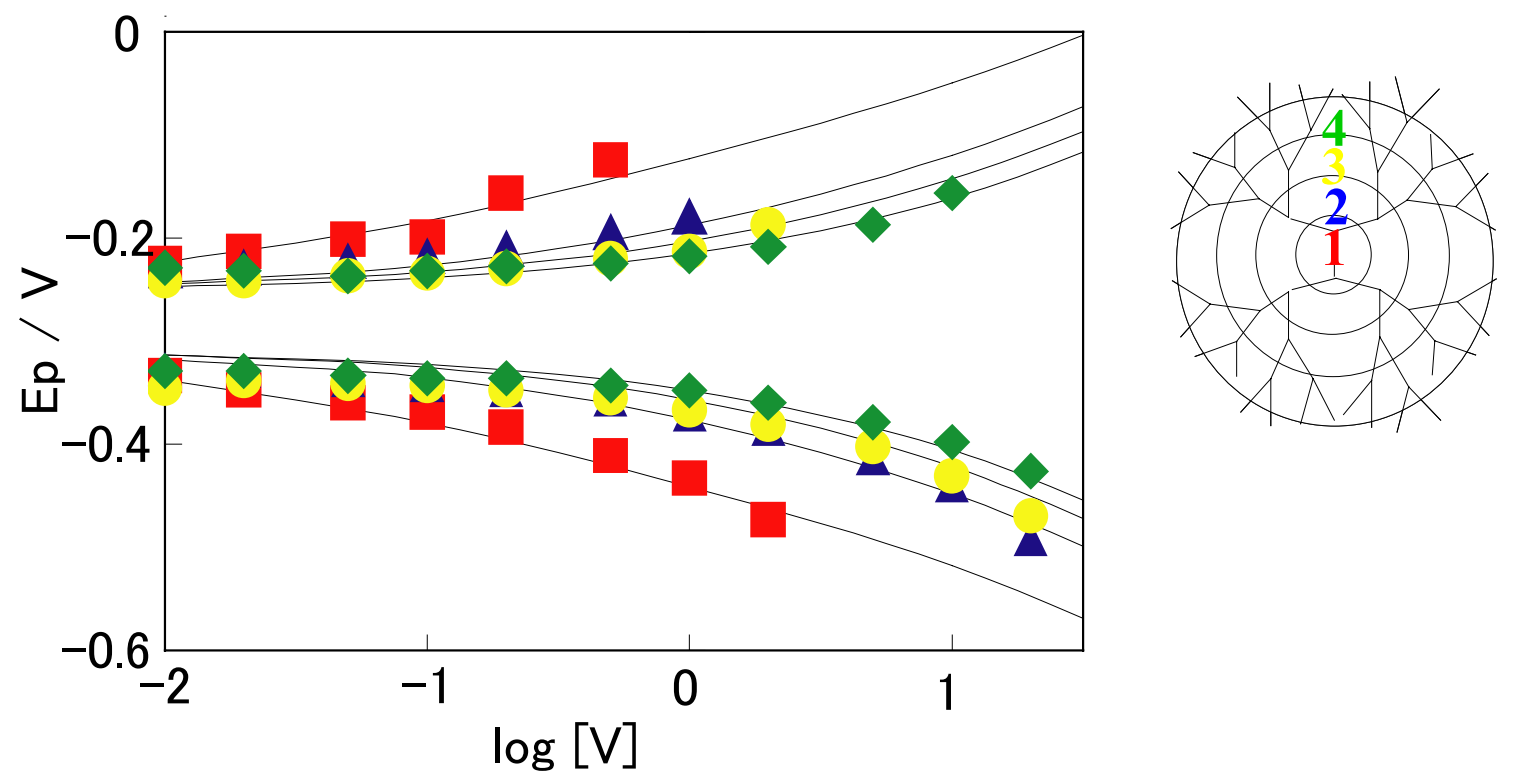

Figure S10. $\mathrm{Fe}^{2+} / \mathrm{Fe}^{3+}$ oxidation and reduction potentials of $\left(\mathrm{FeCl}_{3}\right)_{\mathrm{n}} @$ DPA G4 at various scan rates. $\square ; \mathrm{n}=2(\mathrm{FeCl}$ filled the first generation of DPA G4), $\Delta ; \mathrm{n}=6\left(\mathrm{FeCl}_{3}\right.$ filled DPA G4 up to the second generation), $\bullet$; $n=14$ (up to the third generation), $\bullet \mathrm{n}=30$ (up to the fourth generation). Lines are the simulated curves to determine electron transfer rate constants $\boldsymbol{k}_{\boldsymbol{s}}$ (Table S2). $\left[\mathrm{FeCl}_{3}\right]=0.5 \mathrm{mM}$. The $\boldsymbol{k}_{\boldsymbol{s}}$ increases when the higher generation is filled with $\mathrm{FeCl}_{3}$. 
Table S2. Electron transfer rate constants $\boldsymbol{k}_{\boldsymbol{s}}$ of $\left(\mathrm{FeCl}_{3}\right)_{\mathrm{n}} @ \mathrm{DPA}$ G4 $(\mathrm{n}=2,6,14,30)$. The $\boldsymbol{k}_{\boldsymbol{s}}$ was determined by fitting simulation curves using the commercial BAS DigiSim Simulator $3.03^{4}$ in Figure S10. The default numerical option with the assumption of planar diffusion was used in the framework of an $\mathrm{E}$ mechanism $\left(\mathrm{Fe}^{3+}+\mathrm{e}^{-}=\mathrm{Fe}^{2+}\right)$. The Butler-Volmer law was considered for the electron-transfer kinetics. The coefficient, $\alpha$, was taken as 0.5 because the difference between the peak potentials and the $\mathrm{E}^{\mathrm{o}}$ remain small (lower than $\left.100 \mathrm{mV}\right)^{5}$. The average distance $[\AA]$ from the core to imine site at each generation was estimated from a molecular model which we preciously reported ${ }^{1}$. The molecular modeling of DPA G4 was performed based on the crystal structure of DPA G2. The average distance of the complexing site from the outer shell was determined on the basis of the assumption that $\mathrm{FeCl}_{3}$ is stepwise coordinated to the inner imines. A plot of $\ln \boldsymbol{k}_{\boldsymbol{s}}$ vs. distance $\boldsymbol{r}[\AA]$ (Figure 2) gives a straight line corresponding to the Marcus theory, which means that the radial stepwise complexation is confirmed. This time $\boldsymbol{r}$ is estimated based on the hypothesis that the size of DPA does not change during the complexation.

\begin{tabular}{lllll}
$\mathrm{n}$ & $\mathrm{E}^{\mathrm{o}}[\mathrm{V}] \mathrm{vs} \mathrm{Fc} / \mathrm{Fc}^{+}$ & $\boldsymbol{k}_{s}\left[\mathrm{~cm} \mathrm{~s}^{-1}\right]$ & \multicolumn{2}{l}{$\begin{array}{l}\text { The average distance }[\AA] \text { of imine site from } \\
\text { core }\end{array}$} \\
\hline 2 & -0.280 & 0.0015 & 1.52 & 13.7 \\
6 & -0.280 & 0.006 & 7.20 & 8.00 \\
14 & -0.280 & 0.010 & 11.2 & 4.04 \\
30 & -0.280 & 0.015 & 12.8 & 2.40
\end{tabular}

${ }^{4}$ Rudolph, M.; Reddy, D. P.; Felberg, S. W. Anal. Chem. 1994, 66, 589A.

5 Bellec, N.; Boubekeur, K.; Carlier, R.; Hapiot, P.; Lorcy, D.; Tallec1a, A. J. Phys. Chem. A 2000, 104, 9750.

Savéant, J.-M.; Tessier, D. Faraday Discuss. Chem. Soc. 1982, 74, 57. 


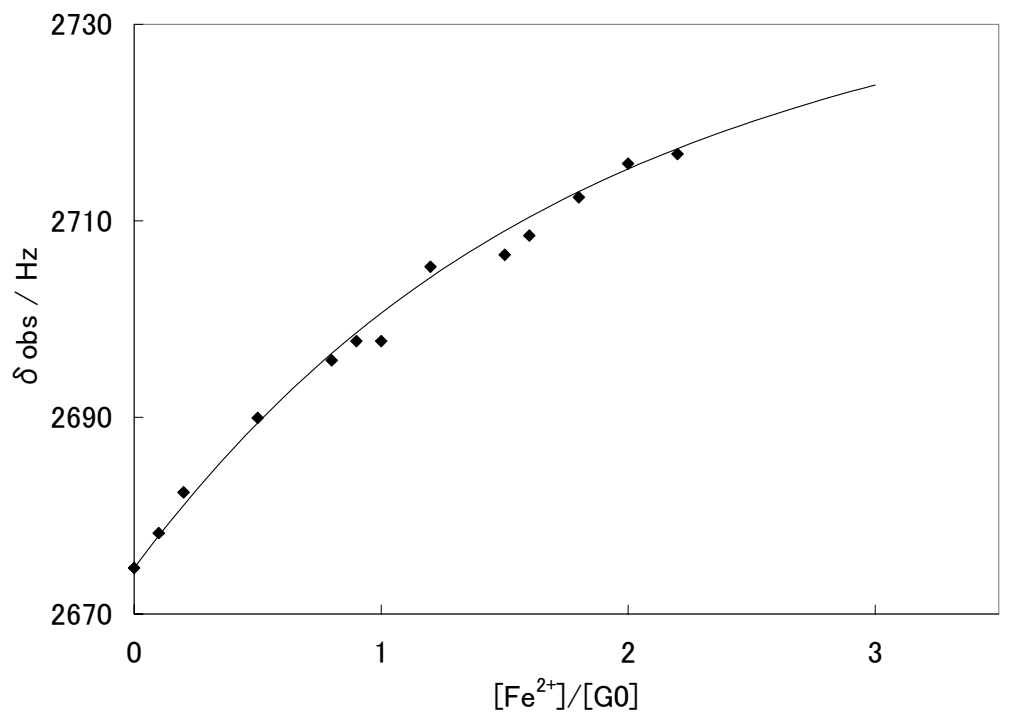

FigureS11. Chemical shifts in ${ }^{1} \mathrm{H}$ NMR spectra of $\mathrm{FeCl}_{2}$ and DPA G0. When proportion $[\mathrm{Fe}] /[\mathrm{G} 0]$ ratio became bigger, upfield shift was observed. The observed chemical shifts of DPA G0 are the weighted average of the chemical shift of free DPA G0 and the chemical shift of the complex under conditions of fast exchange on the NMR time scale ${ }^{6}$.

$$
\begin{aligned}
& \delta_{\text {obsd }}=X_{\mathrm{f}} \delta_{\mathrm{f}}+\left(1-\mathrm{X}_{\mathrm{f}}\right) \delta_{\mathrm{c}} \\
& \mathrm{F}=\Sigma_{\mathrm{i}}\left(\delta_{\mathrm{obsd}, \mathrm{i}}-\mathrm{X}_{\mathrm{f}}, \delta_{\mathrm{f}}-\left(1-\mathrm{X}_{\mathrm{f}}\right) \delta_{\mathrm{c}}\right)^{2}
\end{aligned}
$$

The association constant $\mathrm{K}$ was calculated by minimizing the function $\mathrm{F} .\left(\mathrm{K}=\mathrm{ca} \cdot 0.8 \mathrm{M}^{-1}, \delta_{\mathrm{c}}=\mathrm{ca} .2750 \mathrm{~Hz}\right)$

${ }^{6}$ De Boer, J. A. A.; Reinhoudt, D. N. J. Am. Chem. Soc. 1985, 107, 5347. 